\title{
ФОТОХРОМНЫЕ ОРГАНО-СИЛИКАТНЫЕ НАНОЧАСТИЦЫ
}

\section{В. А. Барачевский}

ВАЛЕРИЙ АЛЕКСАНДРОВИЧ БАРАЧЕВСКИЙ - к.ф.-м.н., с.н.с., ведущиий научный сотрудник, заведующиий лабораторией Центра фотохимии ФНИЦ «Кристаллография и фотоника» РАН, старший научнылй сотрудник ФГБУН Межведомственного ијентра аналитических исследований в области физики, химии и биологии при Президиуме РАН. E-mail: barachevsky@mail.ru.

119421, г. Москва, ул. Новаторов, 7а, к.1, Центр фотохимии ФНИЦ «Кристаллография и фотоника» РАН.

117997, г. Москва, ул. Профсоюзная, д. 65, стр. 6, ФГБУН Межведомственный ичентр аналитических исследований в области физики, химии и биологии при Президиуме Российской академии наук (МЦАИ РАН).

Представлен анализ последних достижений в области разработки фотохромных наночастии диоксида кремния и их применения.

Ключевые слова: фотохромизм, спектры поглощения, спектры флуоресценции, механизм превращений, наночастицы, диоксид кремния.

\section{PHOTOCHROMIC ORGANO-SILICA NANOPARTICLES}

\author{
V.A. Barachevsky \\ 7A, Novatorov st., b. 1, Moscow, 119421, Russia. Photochemistry Center of FSRC "Crystallography and Photonics" \\ of the Russian Academy of Sciences. \\ 65, Profsoyuznaya st., Moscow, 117997, Russia. Interdepartment Center of Analytical Research in the field of \\ Physics, Chemistry, and Biology, Presidium of Russian Academy of Sciences.
}

The analysis of the resent advances in the field of the development of photochromic silica nanoparticles is presented.

Key words: photochromism, absorption spectra, fluorescence spectra, transformation mechanism, nanoparticles, silica.

\section{Введение}

В последние годы значительный практический интерес привлекают фотохромные наночастицы, которые испытывают обратимое фотоиндуцированное изменение своих свойств $[1,2]$. Одним из направлений их разработки является создание фото- хромных наночастиц на основе наночастиц диоксида кремния (ДК). Такие наночастицы используются в биомедицинских исследованиях [3], для получения фотохромных тканей [4] и других целей.

Данная статья представляет обзор с анализом результатов исследований, выполненных в этом направлении. 


\section{Структура и свойства фотохромных силикатных наночастиц}

Наночастицы ДК могут использоваться для получения фотохромных наночастиц, проявляющих как положительный, так и отрицательный фотохромизм. Наночастицы первого типа обратимо окрашиваются под действием УФ излучения, а наночастицы второго типа обратимо обесцвечиваются при возбуждении видимым светом.

\section{Наночастищь со спиропиранами}

В большинстве случаев фотохромные наночастицы проявляют положительный фотохромизм. Их получение основано на физическом или химическом взаимодействии молекул термически обратимых спиропиранов с поверхностью наночастиц ДК. Фотохромные превращения соединений этого типа, в частности СП 1 заключаются в фотоиндуцированном разрыве -C-О-связи в пирановом фрагменте бесцветной циклической формы $\mathbf{A}$ и последующей темновой иис-транс-изомеризации с образованием окрашенной мероцианиновой формы В (схема 1) [2].

При отключении активирующего УФ излучения фотоиндуцированная мероцианиновая форма $\mathbf{B}$ спонтанно возвращается в исходное бесцветное состояние. Скорость обесцвечивания возрастает при облучении видимым сетом или при нагревании.
Такой положительный фотохромизм с высокой скоростью темновой релаксации фотоиндуцированной формы В проявляют латексные пленки, содержащие частицы ДК размером 3-5 мкм с введенными в них молекулами спиропирана СП 1 [5].

Сравнительное исследование фотохромных превращений спиропиранов СП 2-СП 4 с различными заместителями при атоме азота индолинового фрагмента в матрице ДК - пергидрополисилозана показало, что в отличие от октодецил-содержащего спиропирана СП 2, гидроксил- (СП 3) и карбоксил- (СП 4) замещенные соединения характеризуются низкой скоростью спонтанного обесцвечивания мероцианиновой формы [6].<smiles>[R]N1c2ccccc2C2(C=Cc3cc([N+](=O)[O-])ccc3O2)C1(C)C</smiles>

$\mathrm{C}$ 2: $\mathrm{R}=\left(\mathrm{CH}_{2}\right)_{17} \mathrm{CH}_{3}$ CП 3: $\mathrm{R}=\left(\mathrm{CH}_{2}\right)_{2} \mathrm{OH}$ $\mathrm{C} \Pi 4: \mathrm{R}=\left(\mathrm{CH}_{2}\right)_{2} \mathrm{COOH}$

Как показано на схеме 2, в случае спиропиранов СП 3 (а) и СП 4 (б) это обусловлено образованием водородных связей между гидроксильной или карбоксильной группами и кислородом ДК.

Положительный фотохромизм проявляют молекулы спиропирана СП 5, присоединенные к наночастицам ДК размером 927 нм посредством полимерного полиметилметакрилатного спейсера [7-9]. При этом фотовозбуждение можно осуществлять двухфотонным способом лазерным излучением с длиной волны излучения 780 нм [8].<smiles>CN1c2ccccc2C(C)(C)C12C=Cc1cc([N+](=O)[O-])ccc1O2</smiles>

A

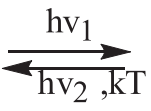

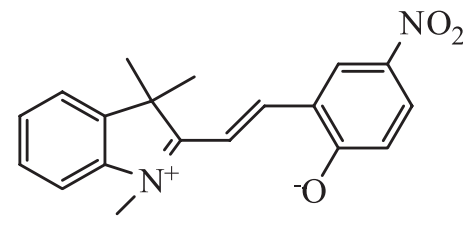

$\mathrm{B}$

Схема 1. Фотохромные превращения спиропирана СП 1 с положительным фотохромизмом

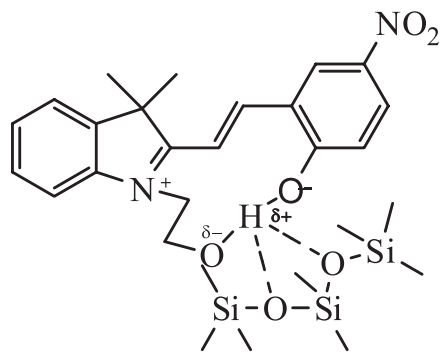

(a)

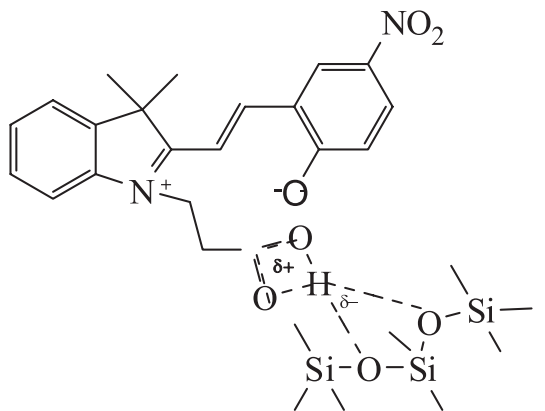

(6)

Схема 2. Структуры адсорбатов мероцианиновых форм СП 3 (а) и СП 4 (б) с поверхностью ДК 


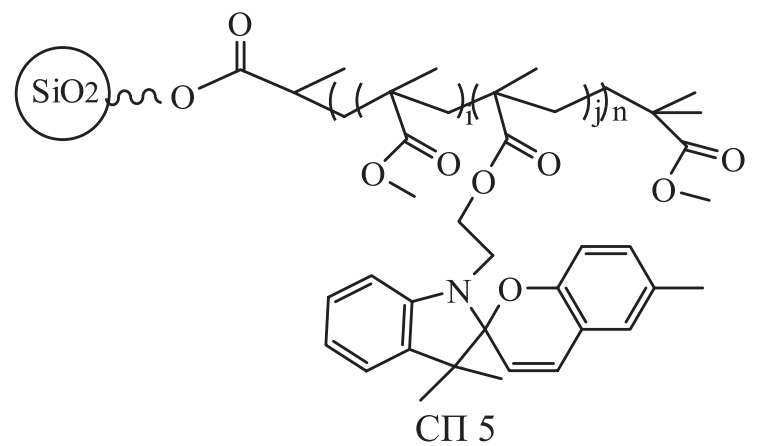

Установлено, что наиболее эффективные фотохромные превращения наблюдаются для полимерных цепей, содержащих 20 \% спиропирановых и $80 \%$ метилметакрилатных фрагментов.

Подобные фотохромные свойства проявляют силилированные спиропираны СП 6 и СП 7 с длинными метиленовыми спейсерами, ковалентно связанными с наночастицами ДК [10].

Выяснено, что скорость темнового обесцвечивания мероцианиновой формы спиропирановых фрагментов возрастает с увеличением длины спейсера и зависит от полярности растворителя. Сравнительное исследование фотохромизма длинноцепочечного спиропирана СП 8 и фотохромных наночастиц на его основе в этиленгликоле показало, что в отличие от фотохромной наночастицы соединение СП 7 в этом растворителе проявляет отрицательный фотохромизм (рис. 1) [11].

Результаты спектрально-кинетического исследования фотохромизма спиропирана СП 9 в водноэтанольных растворах без и в присутствии наночастиц ДК свидетельствуют о химическом характере

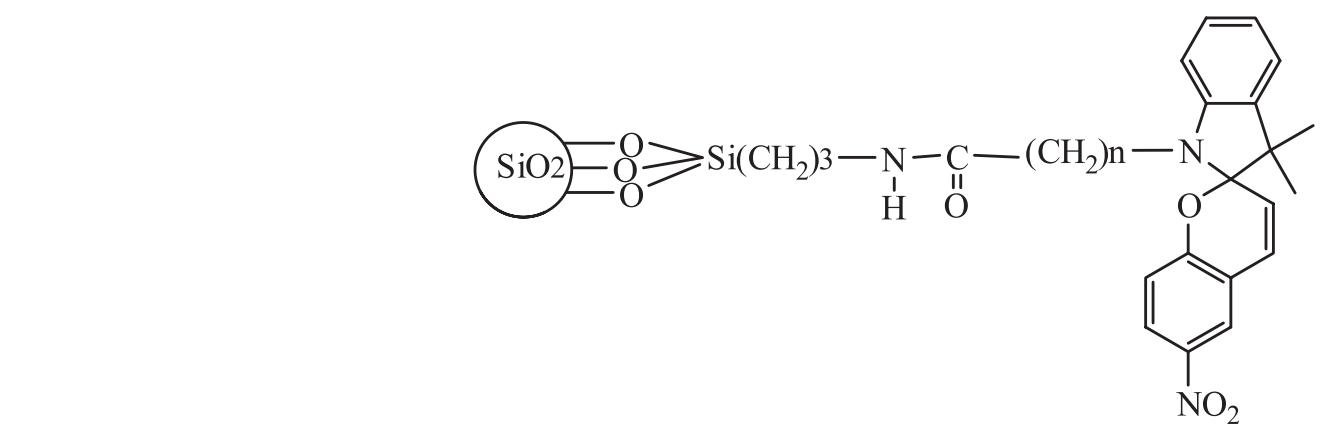

СП 6: $\mathrm{n}=2 ; \mathrm{C} \Pi 7: \mathrm{n}=10$<smiles>CCN(C)C(C)C(=O)N1c2ccccc2OC12C=Cc1cc([N+](=O)[O-])ccc1C2(C)C</smiles>

СП 8<smiles>COc1cc([N+](=O)[O-])cc2c1OC1(C=C2)N(C)c2ccccc2C1(C)C</smiles>

СП 9

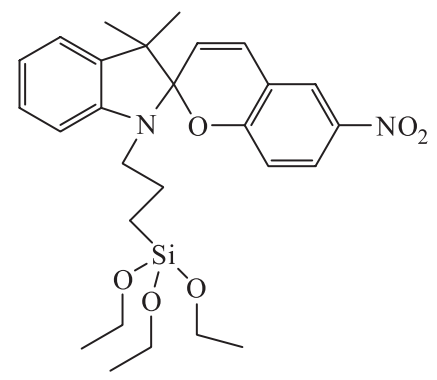

СП 10
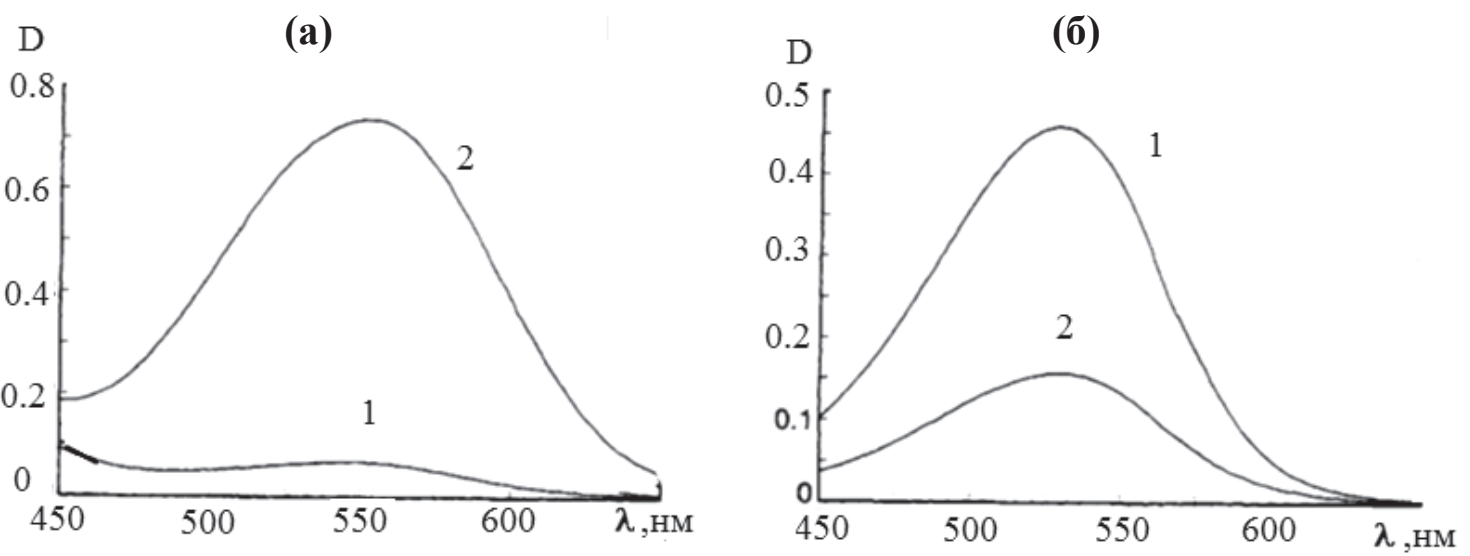

Рис. 1. Спектры поглощения фотохромных наночастиц со СП 7 (а) и фотохромного соединения СП 8 (б) в этиленгликоле до (1) и после облучения УФ светом (2а) и видимым излучением (2б) 
взаимодействия молекул спиропирана с поверхностью наночастиц ДК (рис. 2) [12].

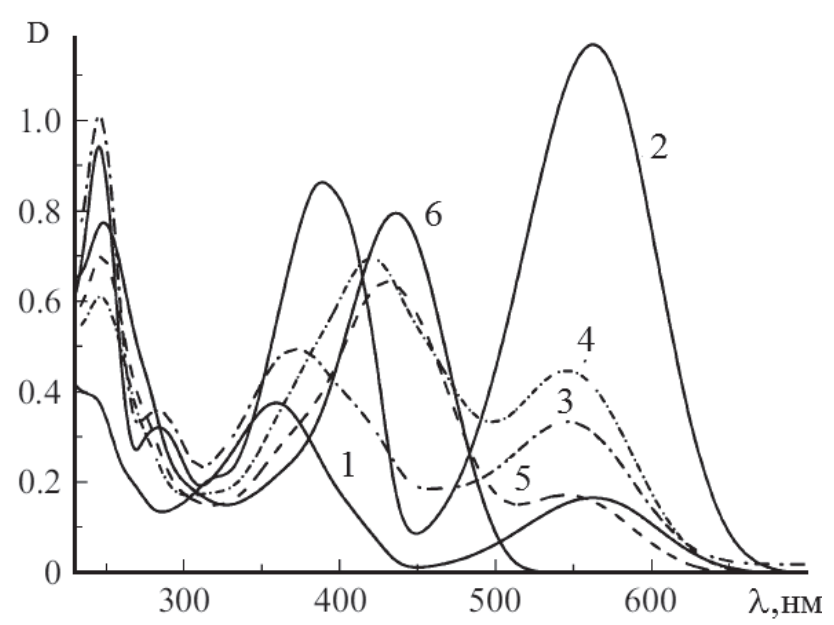

Рис. 2. Спектры поглощения водно-спиртового раствора соединения СП 9 без $(1,2)$ и в присутствии наночастиц ДК (3-6) до (1,3), после УФ

облучения $(2,4)$, воздействия видимым светом (5) и термической релаксации (6)

Из рис. 2 видно, что спиропиран СП 9 в водно-этанольном растворе характеризуется наличием полосы поглощения в видимой области спектра вследствие того, что часть молекул спиропирана в полярном растворителе присутствует в мероцианиновой форме. При добавлении в раствор наночастиц ДК интенсивность длинноволновой полосы поглощения возрастает, а также появляется плечо полосы поглощения при 420 нм (рис. 2, кр. 3). УФ облучение приводит к дальнейшему повышению интенсивности этих полос поглощения (рис. 2, кр.4). Под действием видимого света интенсивность полосы поглощения при 560 нм падает, а поглощение с максимумом при 420 нм возрастает (рис. 2, кр. 5). Полоса, возникающая после длительной темновой релаксации (рис. 2, кр. 6), стабильна и не изменяется под действием УФ и видимого света. Эту полосу поглощения следует отнести к образованию протонированной мероцианиновой фор- мы. Отсутствие отрицательного фотохромизма, возможно, обусловлено агрегацией и кристаллизацией этой формы на поверхности наночастиц ДК.

Фотохромные наночастицы ДК с химически связанными молекулами силилированного спиропирана СП 10 проявляют отрицательный фотохромизм [13].

Отрицательный фотохромизм обнаружен для гидроксил-замещенного спиропирана СП 11 $[14,15]$.

Сразу после введения спиропирана СП 11 в раствор, содержащий ДК, соединение проявляет положительный фотохромизм с появлением фотоиндуцированной полосы поглощения мероцианиновой формы спиропирана (схема 1; рис.3, кр.1).

$$
\mathrm{D}
$$

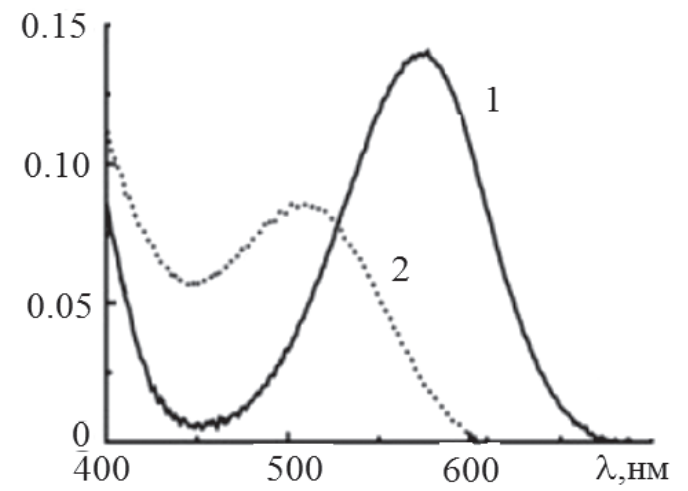

Рис. 3. Спектры поглощения мероцианиновой формы спиропирана СП 11 сразу после введения в раствор ДК (1) и через 312 часов (2)

Однако спустя 312 часов раствор окрашивался с появлением гипсохромно смещенной полосы поглощения мероцианиновой формы (рис. 3 , кр. 2). Максимум спектра поглощения мероцианиновой формы смещался с 574 нм до 510 нм. При этом проявлялся отрицательный фотохромизм (схема 2). Появление окраски раствора связано с протонированием мероцианиновой формы спиропирана СП 11, что подтверждается результатами электрохимических исследований [15].<smiles>CC1(C)c2ccccc2N(CCO)C12C=Cc1cc([N+](=O)[O-])ccc1O2</smiles><smiles>CC1(C)C(/C=C/c2cc([N+](=O)[O-])ccc2O)=[N+](CO)c2ccccc21</smiles>

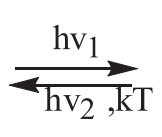

СП 11<smiles>CC1(C)c2ccccc2N(CCO)C12C=Cc1cc([N+](=O)[O-])ccc1O2</smiles>

Схема 3. Схема фотохромных превращений СП 11 с отрицательным фотохромизмом 
Термическая изомеризация спиропирановой формы в мероцианиновую с образованием протонных комплексов мероцианиновой формы наблюдалась в водных [16] и водно-ацетонитрильных [17] растворах гидроксилсодержащих нитрозамещенных спиропиранов.

Отрицательный фотохромизм обнаружен и для покрытий, включающих спиропиран СП 1 и пергидрополисилозан, после превращения последнего в ДК в процессе обработки парами водного раствора аммиака $[18,19]$. Введение в состав покрытия полиметилметакрилата (ПММА) приводило к повышению эффективности фотохромных превращений спиропирана (рис. 4) [20]. С увеличением концентрации ПММА покрытия проявляют не отрицательный, а положительный фотохромизм [21].

D

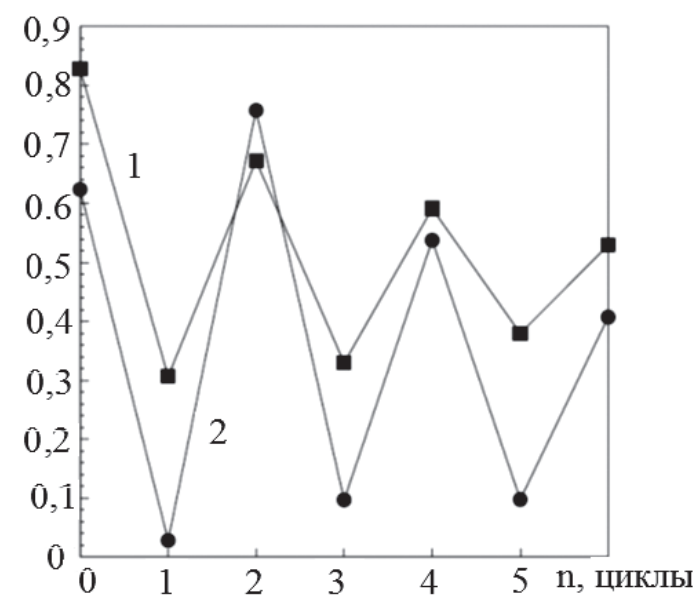

Рис. 4. Модуляция поглощения при 500 нм пленки ДК, содержащей спиропиран СП 1 в ПММА в концентрации 0 (1) и 0.2 вес.\% (2) при попеременном облучении видимым и УФ светом

Нитрозамещенный спиропиран СП 1 использовался для получения мезопористрых силикатных стекол, проявляющих отрицательный фотохромизм вследствие образования протонного комплекса мероцианиновой формы спиропирана с гидроксильными поверхностными группами стекла [22].

Подобные результаты получены с тем же спиропираном в случае использования дендритных волокнистых нанокремнеземов как в растворах (рис. 5) [23], так и твердом состоянии (в клее) [24].

Возможность получения наночастиц с отрицательным фотохромизмом обусловлена наличием на поверхности ДК поверхностных групп, вступающих в специфическое взаимодействие с молекулами фотохромных соединений.

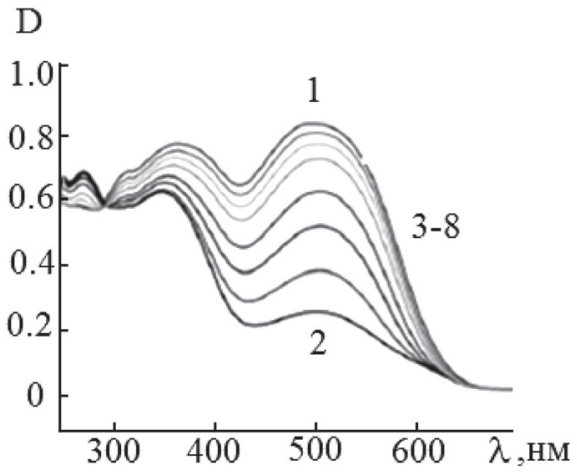

Рис. 5. Фотоиндуцированное изменение спектров поглощения спиропирана СП 1, содержащегося в наночастицах кремнезема, в толуоле до (1), после УФ облучения (2) и темновой релаксации в течение 8,5 часов (3)

С использованием функционализированных силилированных молекул нитрозамещенного спиропирана СП 11 и флуоресцирующего красителя Родамина В были получены наночастицы ДК, обеспечивающие обратимую модуляцию флуоресценции за счет FRET - эффекта (рис. 6) [25].

Фотохромный спиропиран СП 12 был использован для получения фотонных кристаллов на основе золи ДК [26]. Эти кристаллы обеспечивали включение-выключение флуоресценции мероцианиновой формы спиропирана в результате либо фотохромных превращений этого соединения, или при переменном воздействии кислоты и основания.<smiles>CC1(C)c2ccccc2N(CCC(=O)O)C12C=Cc1cc([N+](=O)[O-])ccc1O2</smiles>

Гидрокси-содержащий нитрозамещенный спиропиран СП 9 был использован для получения мезоструктурированных пленок ДК с обратимыми термо- и фотохромными свойствами [27].

\section{Наночастицы со спирооксазинами}

Для получения фотохромных тканей с положительным фотохромизмом использовались соединения из класса спирооксазинов, которые проявляют фотохромные превращения, подобные 


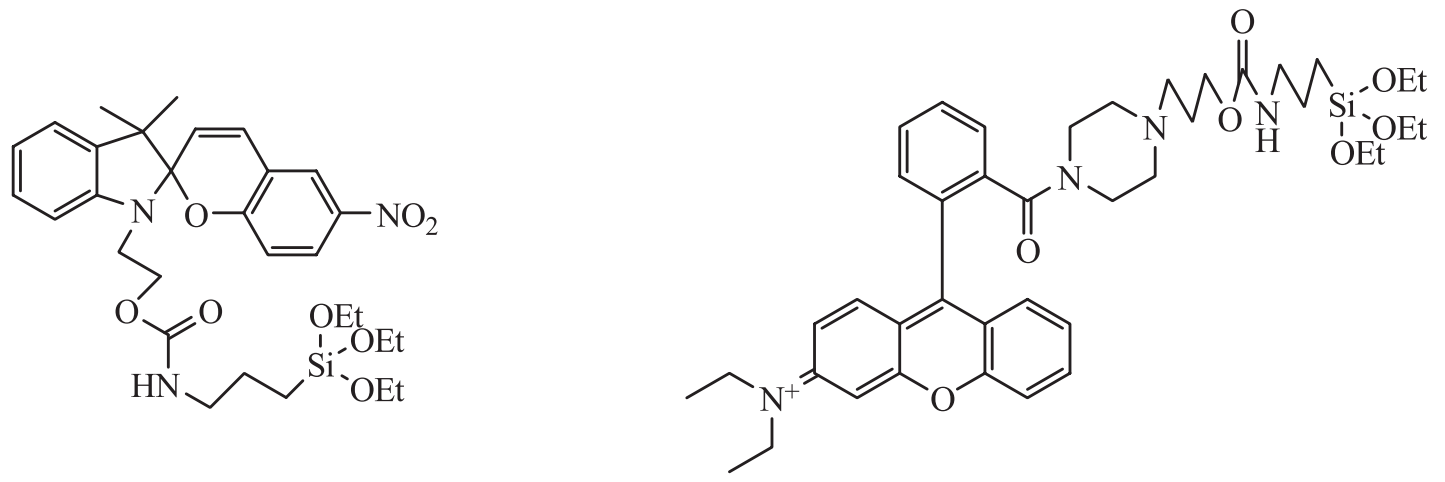

СП 11

Родамин В

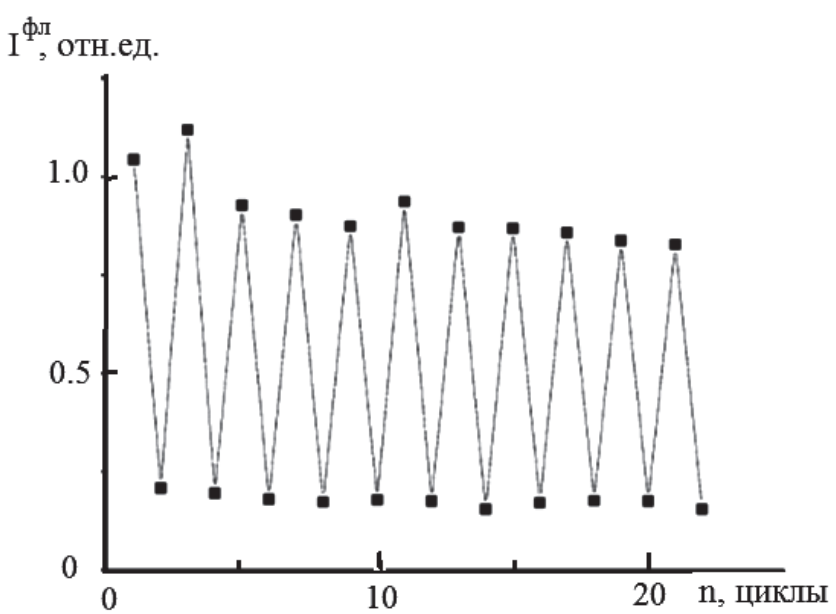

Рис. 6. Модуляция интенсивности флуоресценции Родамина В при 593 нм в водно-этанольном растворе фотохромными превращениями спиропирана СП 11 при попеременном облучении светом с длинами волн 350 и 590 нм

спиропиранам, но отличаются менее выраженной фотодеградацией (схема 4).

Фотохромный спирооксазин СО 1 в водно-этанольном растворе не проявляет спектральных изменений в присутствии наночастиц ДК ни в темноте, ни под действием света [12]. Наблюдаемое снижение скорости темновой релаксации фотоиндуцированной мерооксазиновой формы может свидетельствовать о физической адсорбции молекул на поверхности наночастиц.

Положительный фотохромизм проявляют фотохромные ксерогели на основе спирооксазинов [28]. С использованием спирооксазина СО 2, ко- торый вводился в ксерогель в качестве фрагмента методом фотополимеризации, были получены фотохромные покрытия, содержащие фоточувстви-<smiles>CN1c2ccccc2C(C)(C)C12C=Nc1c(ccc3ccc(OC(=O)CCCC(=O)NCCC[Si](C)(C)O[Si](C)(CCCN[Sn])O[Si](C)(C)CCCN[Pb])cc13)O2</smiles><smiles>CN1c2ccccc2C(C)(C)C12C=Nc1c(ccc3ccccc13)O2</smiles>

CO 1

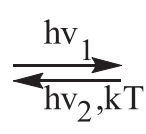

Схема 4. Фотохромные превращения спирооксазина СО 1 
тельные наночастицы ДК [29]. Эти покрытия характеризовались эффективными фотохромными превращениями, высокой прочностью и приемлемой устойчивостью к погодным условиям.

\section{Наночастицы с хроменами}

Наибольшее внимание уделяется созданию фотохромных наночастиц на основе ДК с использованием фотохромных хроменов, которые по сравнению со спиросоединениями обладают высокой устойчивостью к необратимым фотопревращениям. По этой причине они используются в коммерчески успешных фотохромных офтальмологических линзах.

Механизм фотохромных превращений хроменов аналогичен тем, которые описаны выше для спиропиранов и спирооксазинов (схема 5).

Судя по результатам спектрально-кинетического исследования влияния наночастиц на фото- хромизм хромена ХР 1 в водно-этанольном растворе, это соединение испытывает физическую адсорбцию на поверхности наночастиц ДК [12].

Для функционализации наночастиц ДК были синтезированы гидрокси-содержащие хромены ХР 2- ХР 5 и их силилированные аналоги ХР 6-ХР 9 [30].

На их основе были приготовлены соответствующие фотохромные наночастицы ДК, на поверхности которых молекулы находились либо в адсорбированном состоянии вследствие водородной связи с поверхностными гидроксильными группами (а), либо в ковалентно-связанном состоянии (б) (схема 6).

Обнаружено, что все полученные фотохромные наночастицы проявляют фотохромные превращения с двухстадийной темновой релаксацией фотоиндуцированной окрашенной формы.

Наиболее оптимальными фотохромными свойствами обладали силилированные наночастицы $\mathrm{SiO}_{2} @ \mathrm{XP} 8$ и $\mathrm{SiO}_{2} @ \mathrm{XP}$ 9, которые характери-

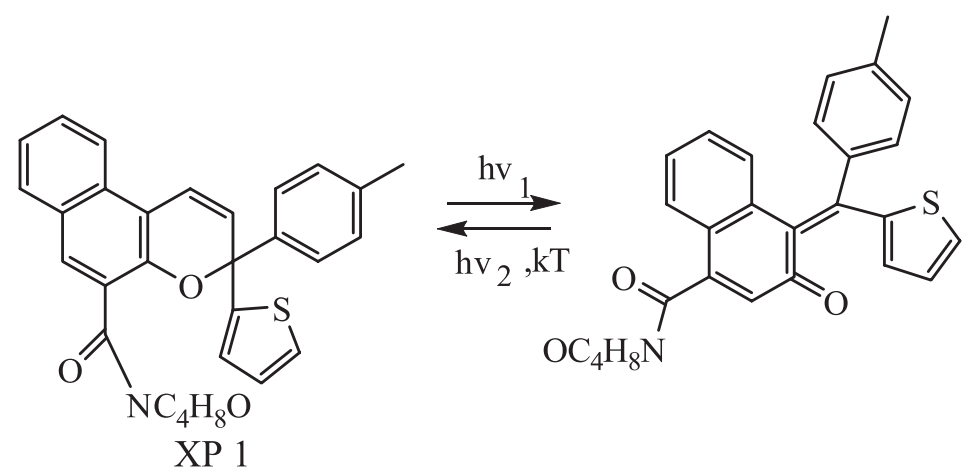

Схема 5. Фотохромные превращения хромена XP 1<smiles>OCc1cc2c(c3ccccc13)OC(c1ccccc1)(c1ccccc1)C=C2</smiles>

XP 2<smiles>CC1(O)c2ccccc2-c2c1c1c(c3ccccc23)OC(c2ccccc2)(c2ccccc2)C=C1</smiles>

XP 3<smiles>[R]C1([R])C=Cc2c(ccc3cc(CO)ccc23)O1</smiles>

$\mathrm{XP}$ 4: $\mathrm{R}=\mathrm{Ph} \quad \mathrm{XP} 5: \mathrm{R}=\mathrm{p}-\mathrm{MeOPh}$<smiles>[R20]#[R]NCCC[Si](OCC)(OCC)OCC</smiles>

XP 6<smiles>CCO[Si]CCCNC(=O)OCCOC1(C)c2ccccc2-c2c1c1c(c3ccccc23)OC(c2ccccc2)(c2ccccc2)C=C1</smiles>

XP 7<smiles>[R]CCCCCNC(=O)OCc1ccc2c3c(ccc2c1)OC([R])([R])C=C3</smiles> 
<smiles>OC1(O)CCCCC1Oc1ccc2c3c(ccc2c1)OC(c1ccccc1)(c1ccccc1)C=C3</smiles>

(a)<smiles>O=C(NCC[SiH]1OC2(O)CCCC(O2)C1O)OCc1ccc2c3c(ccc2c1)OC(c1ccccc1)(c1ccccc1)C=C3</smiles>

(б)

\section{Схема 6. Структуры фотохромных наночастиц ДК на основе хроменов с водородной (а) и химической (б) связями молекул с поверностью наночастиц}

зовались эффективным фотоокрашиванием в течение 1 мин и быстрым темновым обесцвечиванием в течение 2 минут, а также высокой цикличностью фотохромных превращений (рис. 7).

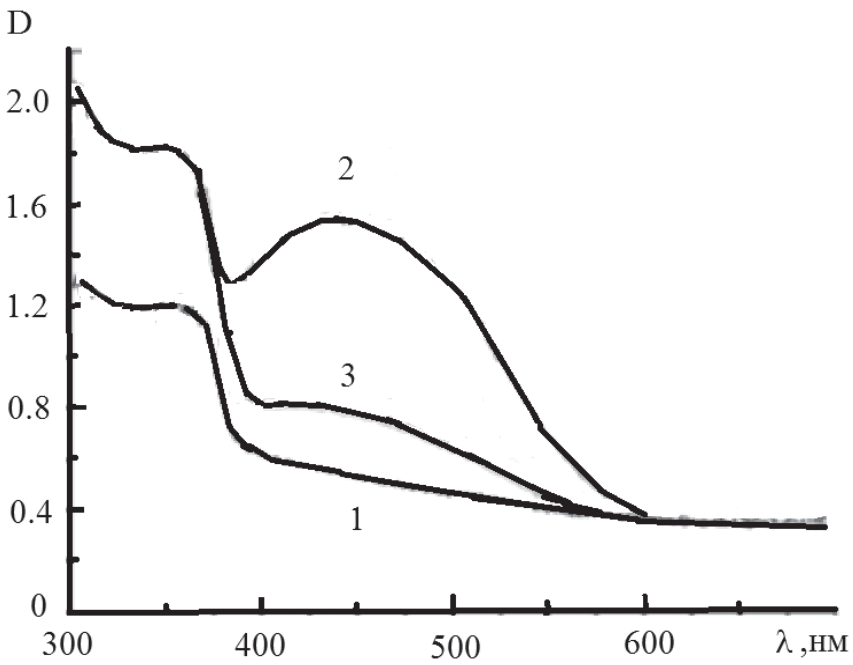

Рис. 7. Спектры поглощения водного раствора фотохромных наночастиц $\mathrm{SiO} @$ @P 8 до (1), после УФ облучения (2) и последующей темновой релаксации (3)

Фотохромные наночастицы $\mathrm{SiO}_{2} @$ XP 6 и $\mathrm{SiO}_{2} @ \mathrm{XP}$ также эффективно окрашивались под действием УФ излучения, но медленно возвращались в исходное состояние (более 2 часов). Наименьшая эффективность фотоокрашивания, сопровождающаяся медленной спонтанной релаксацией фотоиндуцированного состояния в исходное, обнаружена для наночастиц $\mathrm{SiO}_{2} @$ XP 2 и $\mathrm{SiO}_{2} @$ XP 4.

Фотохромные соединения этого типа были использованы для получения чернил для струйной и паст для трафаретной печати на тканях [31]. С использованием фотохромных наночастиц SiO $@$ @X 6 и $\mathrm{SiO}_{2} @$ ХP 7 получены светочувствительные поливинилиден-фторидные волокна [32].
В случае венилиден-содержащих нафтофуранов НФ 1 и НФ 2 наблюдается обратная картина эффективности фотохромных превращений молекул хроменов на поверхности наночастиц ДК с адсорбированными (а) и ковалентно-связанными (б) молекулами фотохромных соединений (схема 7) [33].

Фотохромные превращения обнаружены только для наночастиц с адсорбированными нафтофуранами (рис. 8).

Различие объясняется тем, что в случае адсорбированных молекул, как и в случае растворов [34, 35], протонированные силанольные поверхностные группы при УФ облучении отдают протон фотохромной молекуле, приводя к раскрытию фуранового цикла и образованию третичного катиона нафтофурана, который стабилизируется на поверхности наночастицы (схема 8). В отсутствии фотовозбуждения молекула возвращается в исходное состояние.

В случае фотохромных наночастиц с ковалентно-связанными молекулами нафтофуранов на поверхности наночастиц присутствует незначительное количество силанольных групп, которые могут вступать во взаимодействие с фотохромными молекулами. Кроме того, большое расстояние между фотохромными молекулами и поверхностью наночастиц ДК препятствует стабилизации образующихся катионов.

Нафтофуран НФ 3 без гидроксильной группы также проявляет фотохромные превращения на силикагеле, но не в растворах и не в твердофазных пленках (схема 9) [34].

Спектральные проявления окрашенной формы подобны тем, которые наблюдаются в растворах с добавлением кислоты [35].

\section{Наночастищьы с диарилэтенами}

В отличие от спиросоединений и хроменов фотохромные соединения из класса диарилэтенов 
<smiles>OCc1ccc2c3c(ccc2c1)OC(c1ccccc1)(c1ccccc1)/C3=C/C(c1ccccc1)c1ccccc1</smiles>

НФ 1<smiles>CCO[Si](CC)(OCC)OCCCNC(=O)OCc1ccc2c3c(ccc2c1)OC(c1ccccc1)(c1ccccc1)/C3=C\c1ccccc1</smiles>

НФ 2<smiles>OCc1ccc2c3c(ccc2c1)OC(c1ccccc1)(c1ccccc1)/C3=C\C(=C(c1ccccc1)c1ccccc1)c1ccccc1</smiles>

(a)<smiles>CCO[Si]1(CCCNC(=O)OCc2ccc3c4c(ccc3c2)OC(c2ccccc2)(c2ccccc2)/C4=C\C(c2ccccc2)c2ccccc2)OOc2ccccc2O1</smiles>

(б)

Схема 7. Структуры фотохромных наночастиц ДК на основе нафтофуранов с водородной (а) и химической (б) связями молекул с поверностью наночастиц

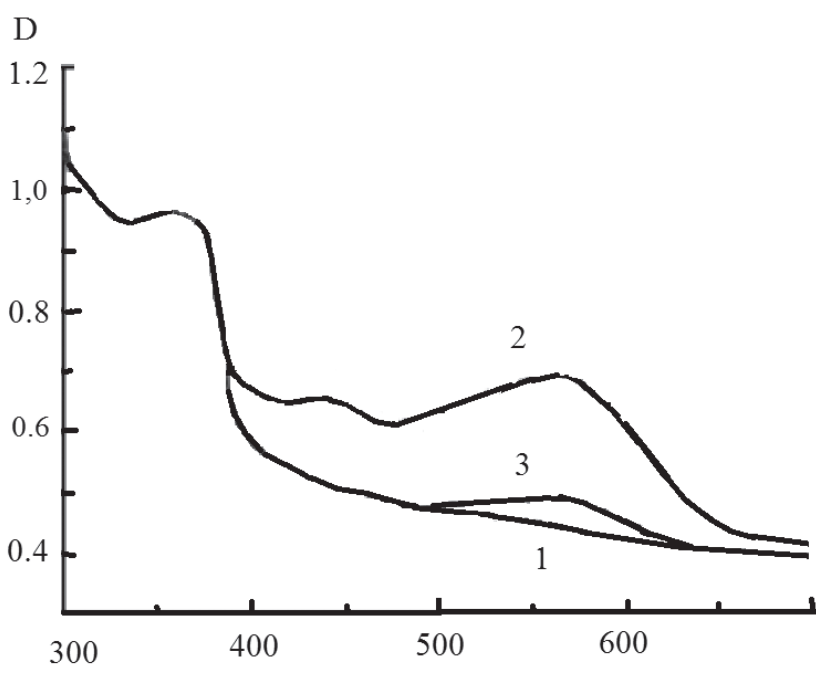

Рис. 8. Спектры поглощения водного раствора фотохромных наночастиц $\mathrm{SiO} @$ @ШФ 1 до (1), после УФ облучения (2) и последующей темновой релаксации (3)

характеризуются термически необратимыми фотопревращениями исходной А и фотоиндуцированной В форм (схема 10).

В результате спектрально-кинетического исследования взаимодействия молекул диарилэтенов ДАЭ 1-ДАЭ 3 в водно-этанольных растворах по- казано, что характер адсорбции молекул этих соединений на поверхности наночастиц ДК зависит от строения молекул и природы заместителей [12].

Диарилэтен ДАЭ 1 , судя по спектрам поглощения открытой и циклической форм, не испытывает ковалентного взаимодействия с поверхностью наночастиц ДК. Однако в отличие от раствоpa, не содержащего наночастиц ДК, для него обнаружена темновая релаксация фотоиндуцированного циклического изомера В в исходную открытую форму А в присутствии наночастиц ДК. Это может свидетельствовать о взаимодействии молекул фотохромного соединения с поверхностью наночастиц ДК.

Для соединений ДАЭ 2 и ДАЭ 3 кроме термической релаксации обнаружены спектральные сдвиги полос поглощения фотоиндуцированных циклических изомеров и появление новых полос поглощения (рис. 9). Подобные результаты получены для твердофазных пленок. Эти результаты свидетельствуют о химической адсорбции функционализированных молекул на поверхности наночастиц ДК.

Для химического связывания молекул диарилэтена с поверхностью ДК, как и в случае спиропиранов и хроменов, осуществляли их силилирование с получением соединения ДАЭ 4 [36]. 


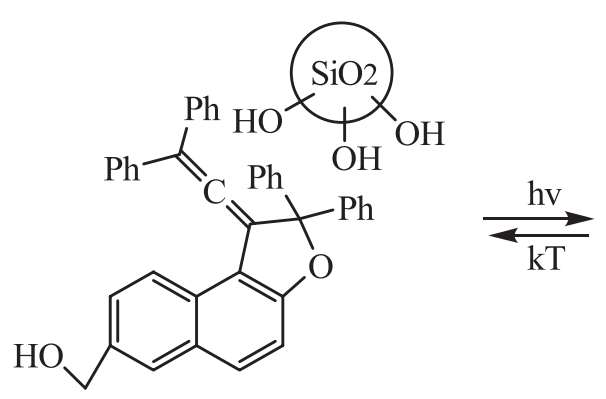<smiles>O=C1C=Cc2cc(CO)ccc2C1=CC(C(=Cc1ccccc1)c1ccccc1)c1ccccc1</smiles>

Схема 8. Фотохромные превращения нафтофураноа НФ 1 на поверхности наночастиц ДК<smiles>CC1(c2ccccc2)Oc2ccc3ccccc3c2/C1=C\c1ccccc1</smiles><smiles>C1=C[C@H]2C[C@@H]1C2</smiles>

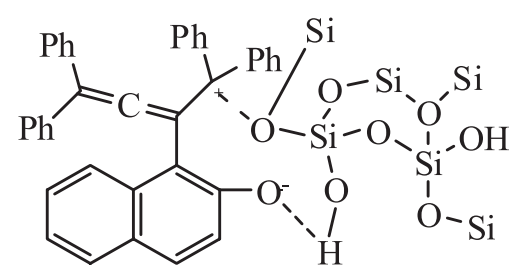

Схема 9. Фотохромные превращения нафтофурана НФ 3 на поверхности наночастиц ДК<smiles>Cc1sc(CO)cc1C1=C(c2cc(CO)sc2C)CCC1</smiles>

A

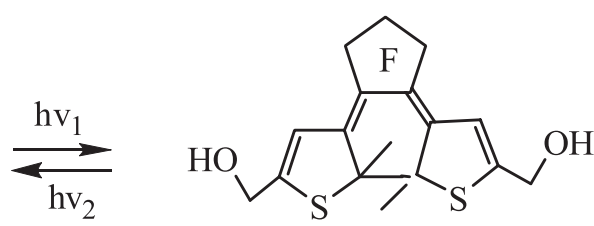

B

ДАЭ 1

Схема 10. Фотохромные превращения диарилэтена ДАЭ 1<smiles>CCc1sc2ccccc2c1C1=C(c2cc(C)sc2C)C(=O)/C(=N/O)C1</smiles>

ДАЭ 2<smiles>Cc1ccc(NC(=S)N/N=N\c2cc(C3=C(c4cc(/C=N/NC(=S)Nc5ccc(C)cc5)sc4C)CCC3)c(C)s2)cc1</smiles>

ДАЭ 3
Изучено фотоиндуцированное изменение абсорбционных и флуоресцентных свойств фотохромных наночстиц ДК, модифицированных молекулами диарилэтена ДАЭ 5 (схема 11), при двухфотонном возбуждении фотохромных превращений. Установлено, что сечение двухфотонного возбуждения молекул составляет 30 GM [37].

С использованием фотохромного диарилэтена ДАЭ 6 были получены фотохромые наноча- 


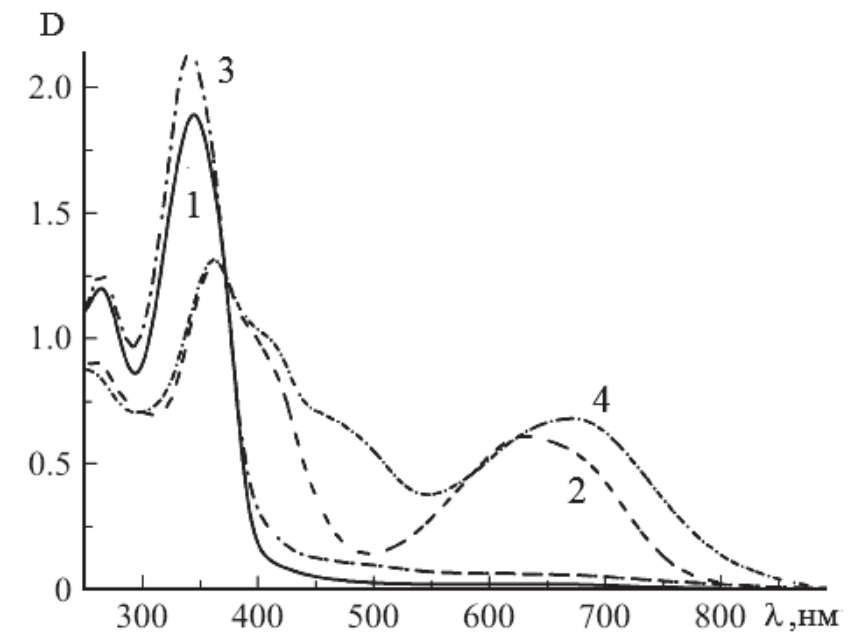

Рис. 9. Спектры поглощения водно-спиртового раствора соединения ДАЭ 3 без $(1,3)$

и в присутствии наночастиц $\mathrm{SiO}_{2}(2,4)$ до $(1,3)$ и после УФ облучения $(3,4)$<smiles>CCO[Si]1(CCCn2cc(COc3ccc(-c4nc(-c5nc(-c6ccccc6)sc5-c5nc(-c6ccccc6)sc5C)c(C)s4)cc3)nn2)Oc2ccccc2O1</smiles>

Схема 11. Структура фотохромной наночастицы ДК на основе диарилэтена ДАЭ 5

Показано, что диада ДАЭ 7, содержащая флуорофор Родамин 101 и фотохромный диарилэтен и химически привитая на поверхности ДК, обеспечивает высокоциклическую модуляцию интенсивности<smiles></smiles>

ДАЭ 4<smiles>C#CCOc1ccc(-c2nc(-c3sc(-c4ccccc4)nc3-c3nc(-c4ccccc4)sc3C)c(C)s2)cc1</smiles><smiles>C=Cc1ccc(C(=O)Oc2ccc(-c3cc(C4=C(c5cc(-c6ccccc6)sc5C)CCC4)c(C)s3)cc2)cc1</smiles>

стицы ДК, покрытые блок-сополимерами (ФНЧ 1 и ФНЧ 2, схема 12) [38].

Эти наночастицы проявляли эффективные фотохромные превращения (рис. 10).

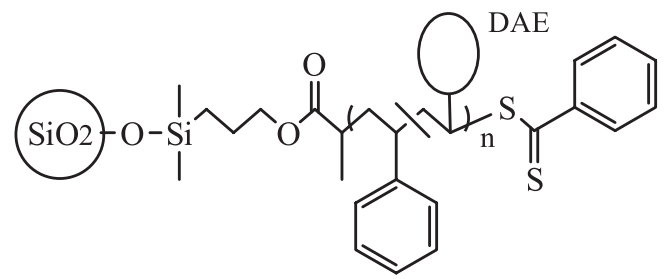

ФНЧ 1 флуоресценции красителя фотохромными превращениями соединения за счет фотоиндуцированного резонансного переноса энергии возбуждения от флуорофора к фотохрому (FRET эффект) (рис. 11) [39].

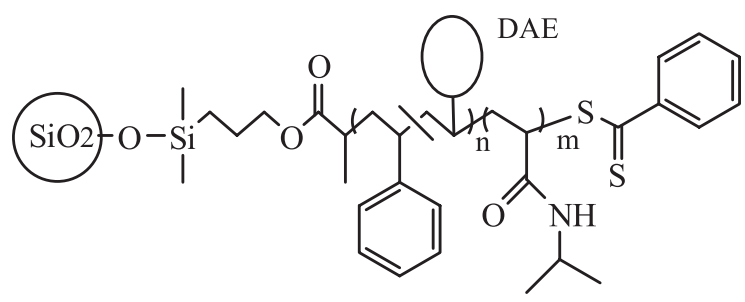

ФРЧ 2

Схема 12. Структуры фотохромных наночастиц ФНЧ 1 и ФНЧ 2 на основе диарилэтена ДАЭ 6 


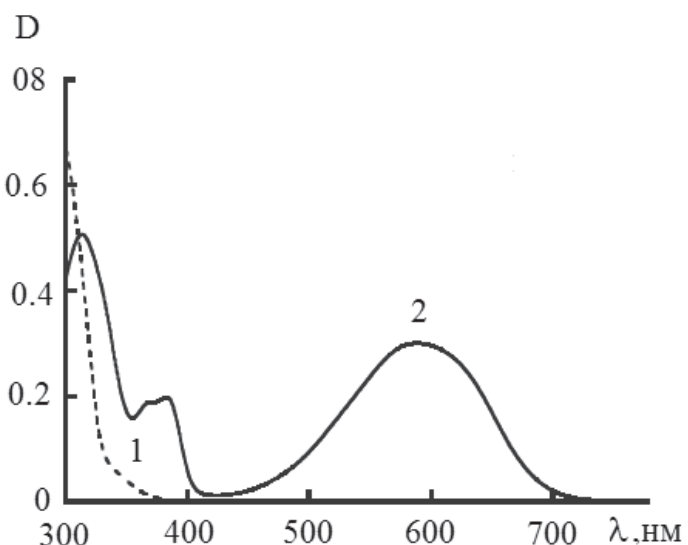

Рис. 10. Спектры поглощения фотохромной частицы ФНЧ 1 в тетрагидрофуране до (1) и после УФ облучения в фотостационарном состоянии

Модуляция интенсивности флуоресценции за счет FRET -эффекта наблюдалась для фуллерен-силикатных фотохромных наночастиц размером 85 нм Ф-1 с химически связанными молекулами диарилэтена (схема 13) [40].

\section{Заключение}

Анализ результатов исследования разработки фотохромных наночастиц ДК свидетельствует об интенсивном развитии этого направления нанофотохромизма гибридных органо-неорганических соединений типа ядро-оболочка. Для их получения были использованы все наиболее известные фотохромные соединения из классов термически обратимых спиропиранов, спирооксазинов и хроменов, а также термически необратимых диарилэтенов. При этом фотохромные наночастицы ДК были получены как путем физической или химической адсорбции молекул на поверхности ДК, так и химической прививкой к поверхности наночастиц.

Особый практический интерес вызывают фотохромные наночастицы ДК с отрицательным фотохромизмом на основе протонированных комплексов спиропиранов, а также наночастицы с химически привитыми молекулами хроменов и нафтофуранов, проявляющие положительный фотохромизм. Создание таких фотохромных наночастиц открывает перспективы разработки<smiles></smiles>

ДАЭ 7

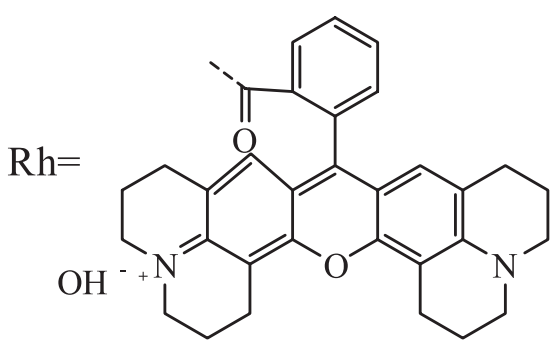

Родамин 101

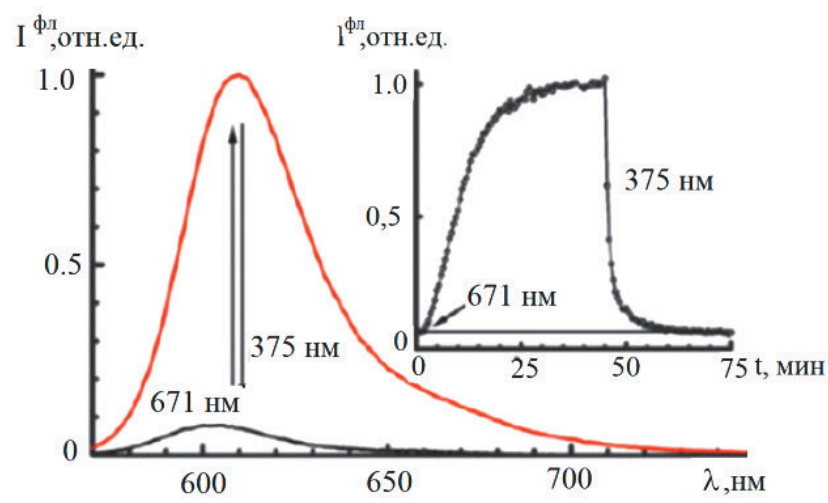

Рис. 11. Фотоиндуцированное изменение спектров флуоресценции и кинетика модуляции флуоресценции (врезка) красителя Родамин 101 фотохромыми превращениями диарилэтенового фрагмента фотохромной диады ДАЭ 7 в этаноле при попеременном облучении УФ (375 нм) и видимым (671 нм) излучениями 


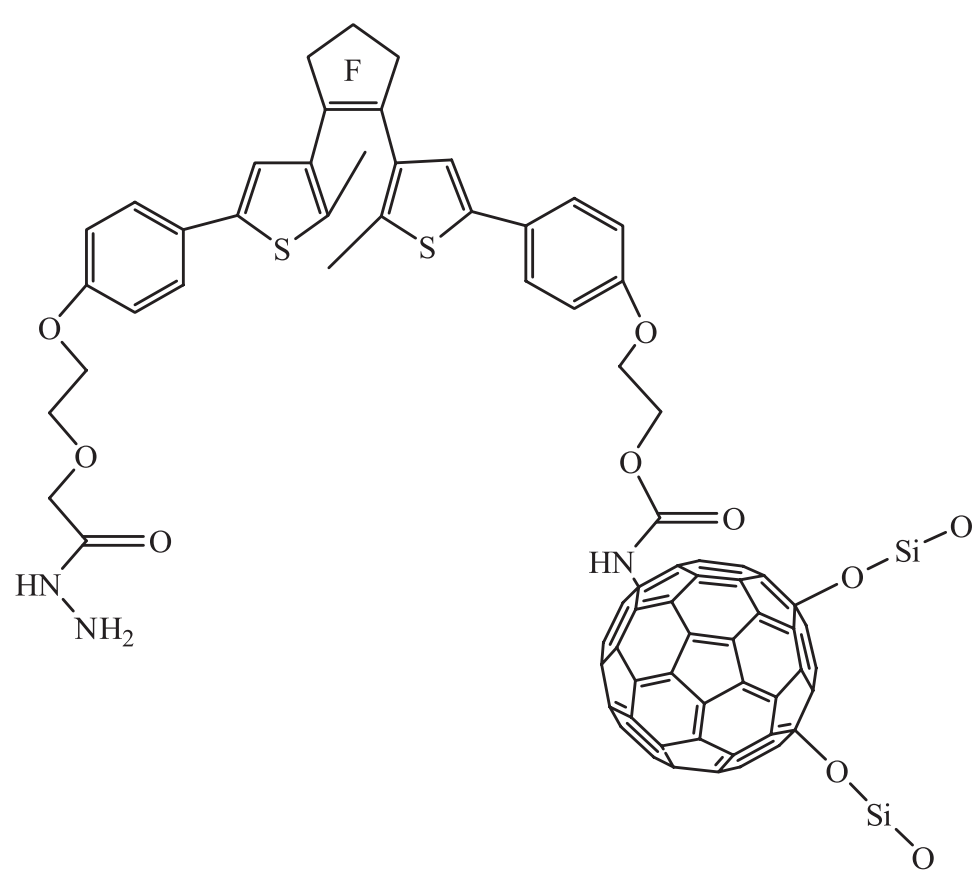

Схема 13. Структура фотохромной наночастицы ДК Ф-1 на основе фотохромного диарилэтена и фуллерена

фотохромных тканей различного функционального применения с динамическим изменением окраски.

Фотохромные наночастицы на основе термически необратимых диарилэтенов, отличающихся от других упомянутых фотохромных соединений рекордной цикличностью фотоуправляемых превращений, могут использоваться для создания фотопереключателей излучения, а также для флуоресцентной визуализации биообъектов.

Работа выполнена при поддержке Российского фонда фундаментальных исследований (проект № 18-03-00650).

\section{Лumepamypa}

1. Barachevsky V.A. Org. Photonics. Photovolt. 2015. V. 3. P. 8.

2. Photochromic Materials: Preparation, Properties and Applications Eds. H. Tian and J. Zhang. Wiley-VCH Verlag GmbH \& Co.Weinheim, Germany. 2016.

3. Cheng H., Yoon J., Tian H. Coord. Chem. Rev. 2018. V. 372 . P. 66.

4. K. Ayazi-Yazdi S., Karimi L., Mirjalili M., Karimnejad M. J. Text. Inst. 2017. V. 108. P. 856.

5. Andersson N., Alberius P., Ortegren J., Lindgremn M., Bergstrom L. J. Mater. Chem. 2005. V. 15. P. 3507.

6. Kinashi K., Harada Y., Ueda Y. Thin Solid Films. 2008. V. 516. P. 2532.

7. Bell N.S,. Piech M. Langmuir. 2006. V. 22. P. 1420.

8. Piech M., George M.C., Bell N.S., Braun P.V. Langmuir. 2006. V. 22. P. 1379.
9. Piech, M. and Bell, N. S., Macromolecules, 2006, V. 39, P. 915.

10. Ueda M., Kudob K., Ichimura K. J. Mater. Chem. 1995. V. 5. P. 1007.

11. Ueda M., Kimbt H.B., Ichimura K. J. Mater. Chem. 1994. V. 4. P. 883.

12. Барачевский В.А., Кобелева О.И., Горелик А.М. Краюшкин М.M. Опт. спектр. 2018. Т. 125. С. 348. [Opt. Spectr. 2018. V. 125. P. 362].

13. Calero P., Aznar E., Lloris J.M., Marcos M.D., Martinez-Manez R., Ros-Lis J.V., Soto J., Sancenon F. Chem. Commun. 2008. V. 14. P.1668.

14. Kinashi K., Nakamura S., Imamura M., Ishida K., Ueda Y. J. Phys. Org. Chem. 2012. V. 25. P. 462.

15. Kinashi K., Nakamura S., Ono Y., Ishida K., Ueda Y. J. Photochem. Photobiol. A. 2010. V. 213. P. 136.

16. Shiraishi Y., Itoh M., Hirai T. J. Phys. Chem. Chem. Phys. 2010. V. 12. P. 13737.

17. Валова Т.М., Барачевский В.А., Хузин А.А., Туктаров. A.P. Журн. общ. химии. 2019. Т. 89. C. 1375 [Rus. J. Gener. Chem. 2019. V. 89. P. 1783].

18. Yamano A., Kozuka H. J. Phys. Chem. B. 2009. V. 113. P. 5769.

19. Yamano A., Kozuka H. J. Phys. Chem. B. 2009. V. 113. P. 10548.

20. Yamano A., Kozuka H. J. Sol-Gel Sci. 2010. V. 53. P. 661.

21. Yamano A., Kozuka H. Thin Solid Films. 2011. V. 519. P. 1772.

22. Okabe Y., Ogawa M. RSC Adv. 2015. V. 5 (123). P. 101789.

23. Yamaguchi T., Maity A., Polshettiwar V., Ogawa M. J. Phys. Chem. A. 2017. V. 121. P. 8080.

24. Yamaguchi T., Maity A., Polshettiwar V., Ogawa M. Inorg. Chem. 2018. V. 57. P. 3671.

25. May F., Peter M., Hutten A., Prodi L., Mattay J. Chem. Eur. J. 2012. V. 18. P. 814. 
26. Zhang Y.Q., Wang J.X., Shang Y.L., Song Y.L., Jiang L. Appl Phys A. 2011. V. 102. P. 531.

27. Malfatti L., Costacurta S., Kidchob T., Innocenzi P., Casula M., Amenitsch H., Dattilo D.D., Maggini M. Micropor. Mesopor. Mater. 2009. V. 120. P. 375.

28. Chang C.-C., Chen L., Cheng L.-P. J. Coat. Technol. Res. 2013. V. 10. P. 73.

29. Suh H.-J., Keum S.-R., Koh K., Kim S.-H. Dyes and Pigments. 2007. V. 72. P. 363.

30. Pinto T.V., Costa P., Sousa C.M., Sousa C.A.D., Monteiro A.A., Pereira C., Soares O.S.G.P., Silva C.S.M., Pereira M.F.R., Coelho P.J., Freire C. ACS Appl. Mater. Interfaces. 2016. V. 8. P. 7221.

31. Pinto T.V., Costa P., Sousa C.M., Sousa C.A.D.C.A.D., Pereira C., Silva C.J.S.M., Pereira M.F.R., Coelho P.J., Freire C. ACS Appl. Mater. Interfaces. 2016. V. 8. P. 28935.

32. Pinto T.V., Cardos N., Costa P., Sousa C.M., Durães N., Silva C., Coelho P.J., C. Pereiraa, C. Freire. Appl. Surf. Sci. 2019. 470. P. 951-958.
33. Pinto T.V., Sousa C.M., Sousa C.A.D., Aboelhassan M.M., Peixoto A.F., Pereira C., Coelho P.J., Freire C. Dalton Trans. 2017. V. 46. P. 9076.

34. Sousa C.M., Berthet J., Delbaere, Coelho P.J. J. Org. Chem. 2013. V. 78. P. 6956.

35. Sousa C.M., Berthet J., Delbaere S., Coelho P.J. Dyes and Pigments. 2017. V. 137. P. 593.

36. Okada H., Nakajima N., Tanaka T.T., Iwamoto M. Angew. Chem. Int. Ed. 2005. V. 44. P. 7233.

37. Ouhenia-Ouadahi K., Laurent G., Barrez E., Yu P., Metivier R., Debarre A. J. Phys. Chem. C. 2018. V. 122. P. 6984.

38. Seno R., Kobatake S. Dyes and Pigments. 2015. V. 114. P. 166.

39. Folling J., Polyakova S., Belov V., van Blaaderen A., Bossi M.L., Hell S.W. Small. 2008. V. 4. P. 134.

40. Jeong J., Yun E., Choi Y., Jung H.-Y., Chung S.J., Song N.W., Chung B.H. Chem. Commun. 2011. V. 47. P. 10668. 